\title{
Clinical Implication of Coronary Artery Calcium Score in Survivors of Out-of-Hospital Cardiac Arrest
}

\author{
Koichiro Matsumura, MD, PhD; Hiromi Kin, MD; Kenichi Fujii, MD, PhD; Hiroki Shibutani, MD; \\ Hiroshi Matsumoto, MD; Munemitsu Otagaki, MD; Mitsuru Yokoi, MD; \\ Yoshihiro Yamamoto, MD, PhD; Tetsuro Sugiura, MD, PhD; Ichiro Shiojima, MD, PhD
}

\begin{abstract}
Background: The aim of this study was to evaluate the clinical ability of coronary artery calcium (CAC) score to identify acute myocardial infarction (AMI) in survivors of out-of-hospital cardiac arrest (OHCA).

Methods and Results: We studied 180 consecutive survivors of OHCA who underwent immediate non-contrast computed tomography $(\mathrm{CT})$ and coronary angiography. Seventy-one patients had ST elevation or left bundle branch block (LBBB; group 1) and 109 patients did not have ST elevation or LBBB (group 2) on post-resuscitation electrocardiogram (ECG). CAC score was significantly higher in AMI compared with non-AMI in groups 1 and 2. The optimal cut-off of CAC score to identify AMI was 11.5 (sensitivity, $80 \%$; specificity, 71\%) in group 1, and 27.4 (sensitivity, $80 \%$; specificity, $76 \%$ ) in group 2 . On multivariate analysis, CAC score was the strongest predictive marker of AMI (OR, 10.91; 95\% Cl: 6.00-25.97). In addition, CAC score was an independent predictor of 30-day survival (OR, 0.38; 95\% Cl: 0.15-0.95).
\end{abstract}

Conclusions: Evaluation of CAC is a useful method to identify AMI in survivors of OHCA, regardless of ST changes on postresuscitation ECG.

Key Words: Acute myocardial infarction; Out-of-hospital cardiac arrest; Resuscitation

$\mathbf{O}$ ut-of-hospital cardiac arrest (OHCA) is a common cause of death, and acute myocardial infarction (AMI) is the leading cause of OHCA. The use of post-resuscitation electrocardiogram (ECG) to identify AMI in OHCA is important, and early coronary angiography $(\mathrm{CAG})$ is recommended in patients with ST elevation or new left bundle branch block (LBBB) on post-resuscitation ECG ${ }^{1-3}$ Because of improved survival and favorable neurological outcome, early CAG is also recommended in patients with high suspicion of AMI, despite lack of ST elevation on post-resuscitation ECG. ${ }^{4,5}$ These guidelines, however, did not specify how to select patients for early CAG, because AMI is often difficult to diagnose on post-resuscitation ECG. Therefore, the clinical implication of early CAG in patients with no evidence of ST elevation is still controversial. ${ }^{6,7}$

Computed tomography (CT) is a screening tool to identify extra-cardiac causes of OHCA in the emergency department. Coronary artery calcium (CAC) score is easily obtained on non-contrast chest $\mathrm{CT}$ and the amount of coronary artery calcification strongly reflects coronary artery plaque volume. ${ }^{8}$ Moreover, a significant correlation between high coronary artery calcification and the presence of AMI was seen in a retrospective study. ${ }^{9}$ Accordingly, the aim of this study was to investigate the predictive value of CAC score to identify AMI in survivors of OHCA.

\begin{abstract}
Methods
Subjects

A total of 250 consecutive patients with OHCA who underwent immediate CT and CAG between January 2011 and December 2018 were enrolled. Because coronary stent and ectopic calcification interfere with precise evaluation of coronary artery calcification, patients with a prior history of coronary artery stent implantation or those on regular hemodialysis $(n=64)$ and those who did not return to spontaneous cardiac rhythm $(n=6)$ were excluded from this study. Informed consent was obtained by an opt-out procedure from all patients. The study protocol was approved by the ethics committee of Kansai Medical University Medical Center and Kansai Medical University.
\end{abstract}

\section{Management}

OHCA patients were given continuous cardiopulmonary resuscitation in accordance with the Basic/Advanced Cardiac Life Support guideline. ${ }^{10-12}$ Patients with continuous cardiac arrest at hospital arrival received extracorporeal membrane oxygenation by the attending emergency physician.

Received June 24, 2019; revised manuscript received June 26, 2019; accepted June 27, 2019; J-STAGE Advance Publication released online July 25, 2019 Time for primary review: 1 day

Department of Cardiology, Kansai Medical University Medical Center, Osaka (K.M., H.K., H.M., M.O., M.Y., Y.Y., T.S.); Division of Cardiology, Department of Medicine II, Kansai Medical University, Osaka (K.F., H.S., I.S.), Japan

Mailing address: Koichiro Matsumura, MD, PhD, Department of Cardiology, Kansai Medical University Medical Center, 10-15 Fumizono-cho, Moriguchi, Osaka 570-8507, Japan. E-mail: kmatsumura1980@yahoo.co.jp

ISSN-2434-0790 All rights are reserved to the Japanese Circulation Society. For permissions, please e-mail: cr@j-circ.or.jp 


\begin{tabular}{|c|c|c|c|}
\hline & $\underset{(n=71)}{\text { Group } 1}$ & $\begin{array}{r}\text { Group 2 } \\
(n=109)\end{array}$ & P-value \\
\hline Age (years) & $68(60-76)$ & $65(55-75)$ & 0.126 \\
\hline Male & $51(72)$ & $85(78)$ & 0.350 \\
\hline BMI $\left(\mathrm{kg} / \mathrm{m}^{2}\right)$ & $23.1(20.1-25.9)$ & $22.0(19.2-24.8)$ & 0.061 \\
\hline \multicolumn{4}{|l|}{ Risk factors } \\
\hline Hypertension & $28(39)$ & $47(43)$ & 0.624 \\
\hline Hyperlipidemia & $17(24)$ & $27(25)$ & 0.900 \\
\hline Diabetes & $21(30)$ & 34 (31) & 0.818 \\
\hline \multicolumn{4}{|l|}{ Characteristics of cardiac arrest } \\
\hline Shockable initial rhythm & $49(69)$ & $75(69)$ & 0.977 \\
\hline Witnessed arrest & $64(90)$ & $100(92)$ & 0.713 \\
\hline Bystander resuscitation & $38(54)$ & $61(56)$ & 0.748 \\
\hline Time to ROSC (min) & $26(11-38)$ & $20(10-34)$ & 0.202 \\
\hline Door-to-CT time (min) & $33(26-49)$ & $30(22-44)$ & 0.142 \\
\hline Door-to-CAG time (min) & $67(50-85)$ & $61(45-90)$ & 0.668 \\
\hline \multicolumn{4}{|l|}{ Laboratory parameters } \\
\hline Serum creatinine $(\mathrm{mg} / \mathrm{dL})$ & $1.1(0.9-1.3)$ & $1.0(0.9-1.3)$ & 0.515 \\
\hline High-sensitivity CRP (mg/dL) & $0.20(0.07-0.78)$ & $0.14(0.05-0.50)$ & 0.362 \\
\hline Troponin I (ng/mL) & $0.24(0.08-1.20)$ & $0.06(0.02-0.23)$ & $<0.0001$ \\
\hline \multicolumn{4}{|l|}{ CAG } \\
\hline Single-vessel CAD & $19(27)$ & $17(16)$ & 0.070 \\
\hline Multiple-vessel CAD & $32(45)$ & $37(34)$ & 0.134 \\
\hline Chronic total occlusion & $7(10)$ & $8(7)$ & 0.553 \\
\hline Collateral flow & $26(37)$ & $21(19)$ & 0.010 \\
\hline AMI & $40(56)$ & $37(34)$ & 0.003 \\
\hline CAC score & $28.8(0-407.9)$ & $3.1(0-178.9)$ & 0.117 \\
\hline 30-day survival & $39(55)$ & $79(72)$ & 0.016 \\
\hline
\end{tabular}

Data given as $n$ (\%) or median (IQR). Group 1, ST elevation or left bundle branch block; Group 2, other electrocardiographic findings. AMI, acute myocardial infarction; BMI, body mass index; CAC, coronary artery calcium; CAD, coronary artery disease; CAG, coronary angiography; CRP, C-reactive protein; CT, computed tomography; OHCA, outof-hospital cardiac arrest; ROSC, return of spontaneous circulation.

Comatose patients who return to spontaneous circulation receive therapeutic hypothermia cooled to target body temperature between $32^{\circ} \mathrm{C}$ and $36^{\circ} \mathrm{C}$ for $>24 \mathrm{~h}$ after achieving target temperature. ${ }^{2}$ Twelve-lead post-resuscitation ECG was obtained, and ST-segment elevation was defined as $\geq 1$-mm elevation in 2 continuous limb leads or $\geq 2 \mathrm{~mm}$ in 2 continuous precordial leads. ST depression was defined as $\geq 0.5$-mm depression in any lead, and T-wave inversion was defined as T-wave inversion in $\geq 2$ continuous leads. Patients with no ST elevation or LBBB were divided into 3 groups according to type of ECG change: ST depression; no ST change; and no ST change but T-wave inversion. ECG was reviewed by a single experienced cardiologist blinded to the angiographic findings. It is standard protocol to perform CAG in all OHCA patients when extra-cardiac cause is ruled out on systemic CT.

\section{Coronary Angiography}

AMI was diagnosed on angiography, on the presence of lesions suggestive of irregular eccentric stenosis with a narrow neck, acute angles or craters, and evidence of thrombus. ${ }^{13,14}$ Culprit lesion, number of diseased vessels in coronary artery disease, chronic total occlusion and collateral flow were identified based on CAG. Initial and final Thrombolysis In Myocardial Infarction (TIMI) grade flow was diagnosed by a single experienced cardiologist blinded to the clinical outcomes. Successful revascularization was defined as residual stenosis $<50 \%$ with TIMI grade 3 flow after percutaneous coronary intervention or successful urgent coronary artery bypass graft. A $>50 \%$ decrease in coronary lesion luminal diameter was considered significant.

\section{Data Collection}

Baseline clinical characteristics and laboratory parameters were extracted from the medical records. Early phase OHCA data were obtained based on Utstein recommendations: initial cardiac rhythm, witnessed cardiac arrest, bystander resuscitation, time from collapse to recovery of spontaneous circulation, and post-resuscitation 12-lead ECG. ${ }^{15}$ Doorto-CT time and door-to-CAG time was also obtained. Left ventricular (LV) wall motion abnormality was evaluated on post-resuscitation echocardiography. Thirty-day survival rate was evaluated.

Non-contrast CT was performed using an 80 multi-detector CT (Aquilion Prime, Canon, Japan) or 64 multi-detector CT (Somatom Perspective, Siemens, Germany) in the emergency department. CAC score was calculated according to Agatston et al. ${ }^{16} \mathrm{CAC}$ score was analyzed semiautomatically in a few minutes with 5-mm slice imaging using dedicated workstations (Virtual Place, AZE, Japan). CAC score was measured by 2 experienced cardiologists who were blinded to the clinical history, and mean CAC score was calculated. 


\begin{tabular}{|c|c|c|c|}
\hline & $\begin{array}{c}\text { Group } 1 \\
(n=40)\end{array}$ & $\begin{array}{c}\text { Group } 2 \\
(n=37)\end{array}$ & P-value \\
\hline Age (years) & $70(63-78)$ & $69(63-76)$ & 0.676 \\
\hline Male & $31(78)$ & $33(89)$ & 0.167 \\
\hline \multicolumn{4}{|l|}{ Risk factors } \\
\hline Hypertension & $12(30)$ & $20(54)$ & 0.032 \\
\hline Hyperlipidemia & $8(20)$ & $11(30)$ & 0.322 \\
\hline Diabetes & $14(35)$ & $16(43)$ & 0.459 \\
\hline \multicolumn{4}{|l|}{ Characteristics of cardiac arrest } \\
\hline Shockable initial rhythm & $30(75)$ & $26(70)$ & 0.642 \\
\hline Witnessed arrest & $36(90)$ & $35(95)$ & 0.448 \\
\hline Bystander resuscitation & $18(45)$ & $25(68)$ & 0.045 \\
\hline Time to ROSC (min) & $29(11-40)$ & $17(11-32)$ & 0.182 \\
\hline Door-to-CT time (min) & $32(27-48)$ & $29(18-43)$ & 0.150 \\
\hline Door-to-CAG time (min) & $73(56-95)$ & $62(38-86)$ & 0.075 \\
\hline Troponin I (ng/mL) & $0.49(0.22-2.30)$ & $0.06(0.02-1.63)$ & 0.003 \\
\hline \multicolumn{4}{|l|}{ Echocardiography } \\
\hline LV focal asynergy & $25(63)$ & $13(35)$ & 0.016 \\
\hline LV diffuse hypokinesis & $12(30)$ & $11(30)$ & 0.979 \\
\hline LV normal wall motion & $3(7)$ & $13(35)$ & 0.002 \\
\hline \multicolumn{4}{|l|}{ CAG } \\
\hline Initial TIMI grade flow 0 or 1 & $28(70)$ & $14(38)$ & 0.004 \\
\hline Culprit lesion in left main trunk & $5(13)$ & $4(11)$ & 0.818 \\
\hline Multiple-vessel CAD & $26(65)$ & $29(78)$ & 0.192 \\
\hline Chronic total occlusion & $3(8)$ & $5(14)$ & 0.386 \\
\hline Collateral flow & $22(55)$ & $19(51)$ & 0.749 \\
\hline Revascularization & $38(95)$ & $33(89)$ & 0.339 \\
\hline Successful revascularization & $25(66)(n=38)$ & $29(88)(n=33)$ & 0.026 \\
\hline CAC score & $101.6(19.3-707.4)$ & $168.1(14.8-743.1)$ & 0.902 \\
\hline 30-day survival & $18(45)$ & $27(73)$ & 0.012 \\
\hline
\end{tabular}

Data given as $n$ (\%) or median (IQR). Group 1, ST elevation or left bundle branch block; Group 2, other electrocardiographic findings. LV, left ventricular; TIMI, Thrombolysis in Myocardial Infarction. Other abbreviations as in Table 1.

\section{Statistical Analysis}

Continuous variables are presented as median (IQR) and categorical variables as $n(\%)$. Differences between the 2 groups were analyzed using the Mann-Whitney U-test for continuous variables and the chi-squared test for categorical variables. Difference between 3 groups was analyzed using Kruskal-Wallis test. To obtain the optimal cut-off predicting AMI, receiver operating characteristic (ROC) curve analysis was performed. Multivariate logistic regression analysis was performed to identify AMI using 8 variables (age; hypertension; hyperlipidemia; diabetes mellitus; shockable initial rhythm; ST elevation or LBBB on postresuscitation ECG; troponin I; and CAC score cut-off). and to identify 30 -day survival using 10 variables (age; hypertension; hyperlipidemia; diabetes mellitus; shockable initial rhythm; witnessed arrest; bystander resuscitation; time to return of spontaneous circulation; door-to-CAG time; and CAC score cut-off). JMP 13.0.0 (SAS Institute, Cary, NC, USA) was used for all statistical analyses. $\mathrm{P}<0.05$ was considered significant.

\section{Results}

\section{Clinical Characteristics}

A total of 180 patients were evaluated: 71 patients had ST elevation or LBBB (group 1) and 109 patients did not have
ST elevation or LBBB (group 2) on post-resuscitation ECG. Clinical characteristics are listed in Table 1. There were no significant differences in the incidence of initial shockable rhythm, door-to-CT time or door-to-CAG time between the 2 groups. There were no significant differences in the laboratory parameters except median troponin I (group $1,0.24 \mathrm{ng} / \mathrm{mL}$; IQR, $0.08-1.20 \mathrm{ng} / \mathrm{mL}$; group $2,0.06 \mathrm{ng} / \mathrm{mL}$; IQR, $0.02-0.22 \mathrm{ng} / \mathrm{mL}, \mathrm{P}<0.0001)$. Thirty-day survival was significantly lower in group $1(55 \%)$ than in group $2(72 \%)$. In patients with AMI (Table 2), there was a significantly higher incidence of echocardiographic LV focal asynergy in group $1(63 \%)$ than in group $2(35 \%)$, whereas the incidence of normal wall motion was significantly higher in group 2 $(35 \%)$ compared with group $1(7 \%)$.

Thirty-day survival rate tended to be lower in AMI patients than in non-AMI patients in group 1 (AMI patients, $45 \%$ vs. non-AMI patients, $68 \% ; \mathrm{P}=0.054)$, whereas it was nearly identical in group 2 (AMI patients, $73 \%$ vs. non-AMI patients, $72 \% ; \mathrm{P}=0.934)$. When patients in group 2 were divided into 3 groups according to type of ECG change (Supplementary Table), there were no significant differences in echocardiography between them.

\section{CAG Characteristics}

There were no significant differences in CAG except the prevalence of collateral flow (group 1,37\%; group 2, 19\%, 
A

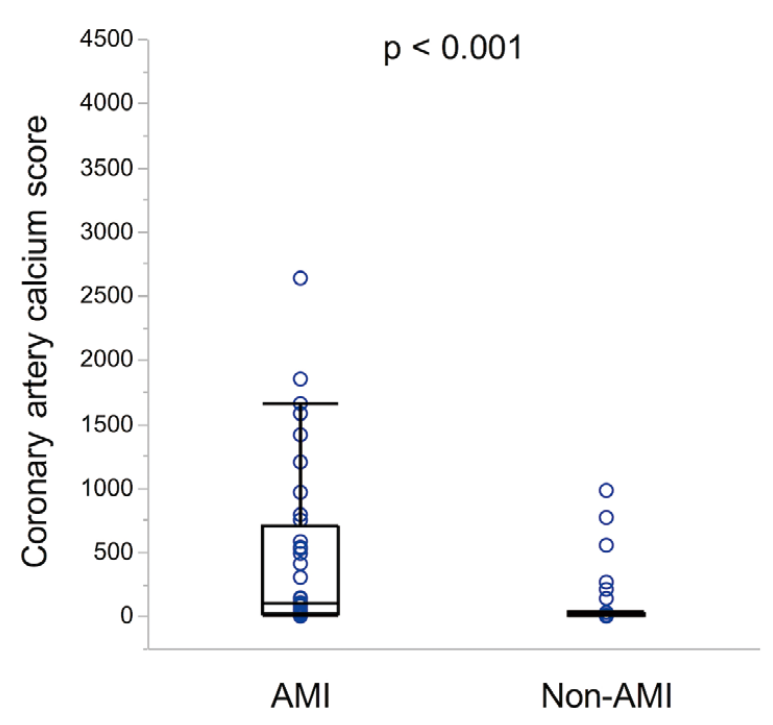

B

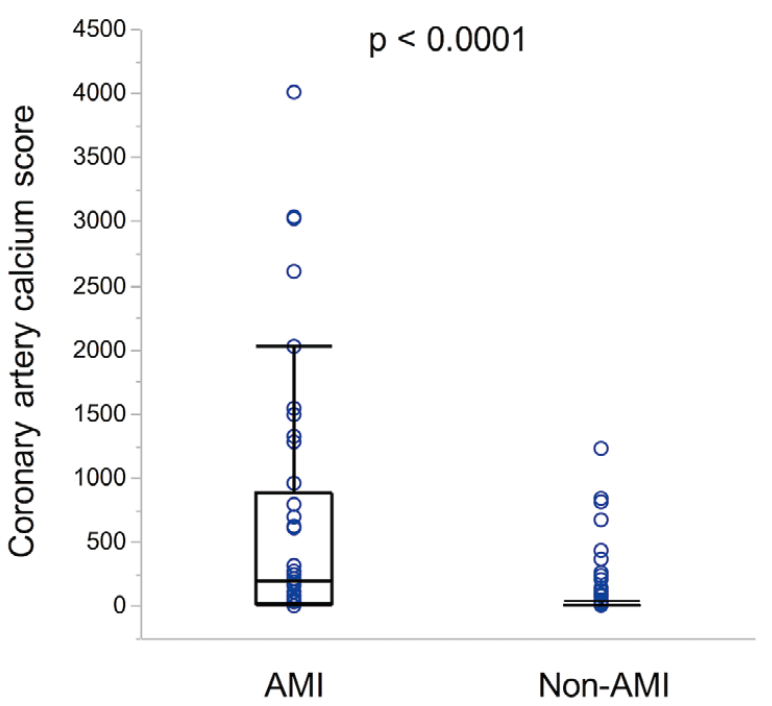

Figure. Coronary artery calcium score vs. presence of acute myocardial infarction (AMI) in patients with (A) ST elevation or left bundle branch block $(n=71)$ and $(\mathbf{B})$ with other electrocardiogram findings $(n=109)$. Box, quartile (25-75th percentile); horizontal line, median.

\begin{tabular}{|lccc|}
\hline Table 3. Multivariate Indicators of AMI in OHCA & & & \\
& OR & $95 \%$ CI & P-value \\
Age (years) & 1.01 & $0.97-1.05$ & 0.541 \\
Hypertension & 0.85 & $0.37-1.93$ & 0.695 \\
Hyperlipidemia & 0.69 & $0.27-1.77$ & 0.443 \\
Diabetes mellitus & 1.61 & $0.67-3.86$ & 0.290 \\
Shockable initial rhythm & 1.93 & $0.78-4.75$ & 0.147 \\
ST elevation or LBBB on post-resuscitation ECG & 2.10 & $0.94-4.67$ & 0.069 \\
Troponin I (ng/mL) & 1.05 & $0.97-1.13$ & 0.102 \\
CAC score cut-off & 10.91 & $4.58-25.99$ & $<0.0001$ \\
\hline
\end{tabular}

ECG, electrocardiogram; LBBB, left bundle branch block. Other abbreviations as in Table 1.

$\mathrm{P}=0.010$, Table 1). There was a significantly higher incidence of AMI in group $1(56 \%)$ compared with group 2 (34\%). Although specificity of post-resuscitation ECG (ST elevation or LBBB) in identifying AMI was $70 \%$, sensitivity was low $(48 \%)$.

In patients with AMI, initial TIMI grade flow was significantly lower in group 1 than in group 2 (initial TIMI grade flow 0 or $1,70 \%$ in group 1 vs. $38 \%$ in group 2 , $\mathrm{P}=0.004$, Table 2). Although both groups had high revascularization, successful revascularization rate was significantly lower in group 1 (successful revascularization rate, $66 \%$ in group 1 vs. $88 \%$ in group $2, \mathrm{P}=0.026$ ).

\section{Predictive Value of CAC Score}

Median CAC score was significantly higher in AMI than in non-AMI in group 1 (AMI, 101.6; IQR, 19.3-707.4 vs. non-AMI, 0; IQR, 0-28.8, $\mathrm{P}<0.001$, Figure $\mathbf{A}$ ) and in group 2 (AMI, 168.1; IQR, 14.8-743.1 vs. non-AMI, 0; IQR, $0-22.0, \mathrm{P}<0.0001$, Figure B). The optimal CAC score cutoff to predict AMI was 11.5 with an area under the curve (AUC) of 0.75 (sensitivity, $80 \%$; specificity, $71 \%$; positive predictive value [PPV], 78\%; negative predictive value [NPV], $73 \%$ ) in group 1, whereas the optimal cut-off was 27.4 with AUC 0.79 (sensitivity, 80\%; specificity, 76\%; PPV, 63\%; NPV, 89\%) in group 2 (Supplementary Figure). On multivariate analysis, CAC score was the strongest predictive marker to identify AMI (OR, 10.91; 95\% CI: 6.00-25.97, $\mathrm{P}<0.0001$, Table 3). In addition, CAC score was an independent predictor of 30-day survival (OR, 0.38; 95\% CI: 0.15-0.95, Table 4).

When LV wall motion was considered, combined CAC score of zero and no LV focal asynergy had higher predictive value to rule out AMI compared with CAC score alone in group 1 (sensitivity, 95\%; specificity, 42\%; PPV, 67\%; NPV, $87 \%$ ) and group 2 (sensitivity, $89 \%$; specificity, $46 \%$; PPV, $44 \%$; NPV, $89 \%)$. A total of 12 of 73 patients $(16 \%)$ with CAC score of zero, however, were diagnosed with AMI.

\section{Discussion}

In survivors of OHCA with ST elevation or LBBB on postresuscitation ECG, improved survival and better neurologi- 


\begin{tabular}{|lccc|}
\hline Table 4. Multivariate Indicators of 30-Day Survival in OHCA & & \\
& OR & $\mathbf{9 5 \%}$ Cl & P-value \\
Age (years) & 1.01 & $0.98-1.05$ & 0.527 \\
Hypertension & 0.45 & $0.17-1.15$ & 0.087 \\
Hyperlipidemia & 0.46 & $0.09-0.75$ & 0.008 \\
Diabetes mellitus & 0.39 & $0.15-1.04$ & 0.056 \\
Shockable initial rhythm & 2.93 & $1.18-7.32$ & 0.019 \\
Witnessed arrest & 4.07 & $1.05-15.81$ & 0.038 \\
Bystander resuscitation & 1.38 & $0.57-3.31$ & 0.473 \\
Time to ROSC (min) & 0.92 & $0.95-1.09$ & $<0.0001$ \\
Door-to-CAG time (min) & 0.99 & $1.00-1.01$ & 0.084 \\
CAC score cut-off & 0.38 & $0.15-0.95$ & 0.034 \\
\hline
\end{tabular}

Abbreviations as in Table 1.

cal outcome was seen in patients who received early CAG compared with delayed CAG., ${ }^{\mathbf{5}, 1,18}$ Indication for early CAG in patients not showing ST elevation, however, is controversial because post-resuscitation ECG is often unreliable to predict AMI in OHCA. In retrospective studies, early CAG was performed in the minority $(34-38 \%)$ of OHCA survivors without ST elevation. ${ }^{19,20}$ Moreover, the majority of patients who received delayed CAG had poor short- and long-term survival. These reports demonstrate that the frequency of early CAG in OHCA without ST elevation is relatively low in the real-world clinical setting. In a retrospective single-center study, however, acute coronary lesion was observed in 33\% of OHCA without ST elevation on postresuscitation ECG. ${ }^{6}$ Also, in the present study AMI was diagnosed in $34 \%$ of OHCA patients without ST elevation or LBBB, but the majority of these patients received revascularization with a high successful revascularization rate. Therefore, in addition to post-resuscitation ECG, it is necessary to identify clinical indicators to select patients who may benefit from early CAG in survivors of OHCA.

Troponin is a specific marker reflecting cardiac injury, but the diagnostic value of troponin in OHCA is unclear because troponin is usually positive on admission not only in patients with cardiac arrest and global ischemia but also in those with subarachnoid hemorrhage. ${ }^{21,22}$ Moreover, many factors such as global ischemia, reperfusion injury, intracranial hemorrhage and acid-base imbalance affect ECG and hide ST changes. ${ }^{23,24}$ In contrast, whole body CT is a common non-invasive assessment for survivors of OHCA in the emergency department. Immediate CT can rule out extra-cardiac causes of OHCA such as respiratory, aortic or neurological causes. ${ }^{25,26}$ Specific care can be provided according to the etiology of cardiac arrest and also facilitates the avoidance of unnecessary thrombolysis or anticoagulation treatments in patients with extra-cardiac cause. Therefore, immediate $\mathrm{CT}$ plays an important role in the emergency department for survivors of OHCA because it can be rapidly obtained after resuscitation with minimal risk. This study has shown that CAC score was significantly higher in OHCA caused by AMI compared with non-AMI, regardless of post-resuscitation ST change.

Although the amount of calcification does not directly reflect the presence of $\mathrm{AMI},{ }^{27} \mathrm{CAC}$ score is related to coronary artery plaque burden, which is a robust predictive marker of coronary events in various populations. ${ }^{28,29} \mathrm{~A}$ meta-analysis has also shown that the patients with detectable coronary artery calcification have higher cardiovascu- lar risk compared with those without. ${ }^{30}$ In the present study, we focused on CAC score using non-contrast CT to predict AMI, and found that CAC score was the strongest predictor of AMI and an independent predictor of 30-day survival. Moreover, on evaluation of CAC score with LV wall motion on echocardiography, a combined CAC score of zero and no LV focal asynergy was found to have a relatively high predictive value to rule out AMI.

When the combination of CAC score zero and no LV focal asynergy was used, $13 \%$ of patients with ST elevation or LBBB and $11 \%$ with no ST elevation or LBBB had AMI. Although CAC score cannot completely select candidates for early CAG, evaluation of CAC score is a useful additional diagnostic method, because conventional methods such as ST changes or elevation of cardiac troponin are unreliable to diagnose AMI. Thus, survivors of OHCA with high CAC score and/or LV focal asynergy, especially those without ST elevation or LBBB on post-resuscitation ECG, should undergo early CAG to benefit from coronary revascularization.

\section{Study Limitations}

Two limitations of the present study should be addressed. First, CAC score was analyzed using 5-mm slice CT. It has been shown that 5-mm slice CT can underestimate coronary artery calcification compared with $3-\mathrm{mm}$ slice, ${ }^{31,32}$ because 5-mm slice non-ECG-gated CT may fail to detect spotty calcification near the culprit lesion. Although CAC score zero may have had higher ability to predict AMI when 3-mm slice ECG-gated CT was used, 5-mm slice CT is often used and is more practical in the emergency department. Furthermore, 3-mm slice ECG-gated chest CT is relatively difficult to perform in patients with unstable post-resuscitation cardiac rhythm. Therefore, 5-mm slice ECG-ungated $\mathrm{CT}$ is a reasonable method in everyday practice. Second, the subjects were limited in number. Although the present results need to be confirmed in a larger group, this is the first study to indicate an association between CAC score and AMI in survivors of OHCA.

\section{Conclusions}

CAC score was a highly sensitive and specific marker to identify AMI in survivors of OHCA. Evaluation of CAC score on immediate CT is useful to identify AMI and to select patients who can benefit from early CAG, despite the absence of ST elevation or LBBB. 


\section{Acknowledgments}

None.

\section{Disclosures}

The authors declare no conflicts of interest.

\section{References}

1. Neumar RW, Shuster M, Callaway CW, Gent LM, Atkins DL, Bhanji F, et al. Part 1: Executive summary: 2015 American Heart Association guidelines update for cardiopulmonary resuscitation and emergency cardiovascular care. Circulation 2015; 132: S315S367.

2. Callaway CW, Donnino MW, Fink EL, Geocadin RG, Golan E, Kern KB, et al. Part 8: Post-cardiac arrest care: 2015 American Heart Association guidelines update for cardiopulmonary resuscitation and emergency cardiovascular care. Circulation 2015; 132: S465-S482.

3. Nolan JP, Soar J, Cariou A, Cronberg T, Moulaert VR, Deakin $\mathrm{CD}$, et al. European Resuscitation Council and European Society of Intensive Care Medicine guidelines for post-resuscitation care 2015: Section 5 of the European Resuscitation Council Guidelines for Resuscitation 2015. Resuscitation 2015; 95: 202-222.

4. Spaulding CM, Joly LM, Rosenberg A, Monchi M, Weber SN Dhainaut JF, et al. Immediate coronary angiography in survivors of out-of-hospital cardiac arrest. N Engl J Med 1997; 336: $1629-1633$

5. Callaway CW, Schmicker RH, Brown SP, Albrich JM, Andrusiek DL, Aufderheide TP, et al. Early coronary angiography and induced hypothermia are associated with survival and functional recovery after out-of-hospital cardiac arrest. Resuscitation 2014 85: $657-663$.

6. Zanuttini D, Armellini I, Nucifora G, Grillo MT, Morocutti G, Carchietti E, et al. Predictive value of electrocardiogram in diagnosing acute coronary artery lesions among patients with out-ofhospital-cardiac-arrest. Resuscitation 2013; 84: 1250-1254.

7. Steg PG, Popovic B. Emergency coronary angiography after outof-hospital cardiac arrest: Is it essential or futile? Circ Cardiovasc Interv 2018; 11: $\mathrm{e} 006804$.

8. Budoff MJ, Achenbach S, Blumenthal RS, Carr JJ, Goldin JG, Greenland P, et al. Assessment of coronary artery disease by cardiac computed tomography: A scientific statement from the American Heart Association Committee on Cardiovascular Imaging and Intervention, Council on Cardiovascular Radiology and Intervention, and Committee on Cardiac Imaging, Council on Clinical Cardiology. Circulation 2006; 114: 1761-1791.

9. Hinzpeter R, Higashigaito K, Morsbach F, Benz D, Manka R, Seifert $\mathrm{B}$, et al. Coronary artery calcium scoring for ruling out acute coronary syndrome in chest pain CT. Am J Emerg Med 2017; 35: 1565-1567.

10. Link MS, Berkow LC, Kudenchuk PJ, Halperin HR, Hess EP, Moitra VK, et al. Part 7: Adult advanced cardiovascular life support: 2015 American Heart Association guidelines update for cardiopulmonary resuscitation and emergency cardiovascular care. Circulation 2015; 132: S444-S464.

11. Perkins GD, Travers AH, Berg RA, Castren M, Considine J, Escalante R, et al. Part 3: Adult basic life support and automated external defibrillation: 2015 international consensus on cardiopulmonary resuscitation and emergency cardiovascular care science with treatment recommendations. Resuscitation 2015; 95: e43-e69.

12. Soar J, Callaway CW, Aibiki M, Böttiger BW, Brooks SC, Deakin CD, et al. Part 4: Advanced life support: 2015 international consensus on cardiopulmonary resuscitation and emergency cardiovascular care science with treatment recommendations. Resuscitation 2015; 95: e71-e120.

13. Radsel P, Knafelj R, Kocjancic S, Noc M. Angiographic characteristics of coronary disease and postresuscitation electrocardiograms in patients with aborted cardiac arrest outside a hospital. Am J Cardiol 2011; 108: 634-638.

14. Zanuttini D, Armellini I, Nucifora G, Carchietti E, Trillò G, Spedicato L, et al. Impact of emergency coronary angiography on in-hospital outcome of unconscious survivors after out-ofhospital cardiac arrest. Am J Cardiol 2012; 110: 1723-1728.

15. Jacobs I, Nadkarni V, Bahr J, Berg RA, Billi JE, Bossaert L, et al. A statement for healthcare professionals from a task force of the international liaison committee on resuscitation (American
Heart Association, European Resuscitation Council, Australian Resuscitation Council, New Zealand Resuscitation Council, Heart and Stroke Foundation of Canada, InterAmerican Heart Foundation, Resuscitation Council of Southern Africa). Resuscitation 2004; 63: 233-249.

16. Agatston AS, Janowitz WR, Hildner FJ, Zusmer NR, Viamonte M Jr, Detrano R. Quantification of coronary artery calcium using ultrafast computed tomography. J Am Coll Cardiol 1990; 15: $827-832$.

17. Larsen JM, Ravkilde J. Acute coronary angiography in patients resuscitated from out-of-hospital cardiac arrest: A systematic review and meta-analysis. Resuscitation 2011; 83: 1427-1433.

18. Hosmane VR, Mustafa NG, Reddy VK, Reese CL 4th, DiSabatino A, Kolm P, et al. Survival and neurologic recovery in patients with ST-segment elevation myocardial infarction resuscitated from cardiac arrest. J Am Coll Cardiol 2009; 53: 409-415.

19. Elfwen L, Lagedal R, James S, Jonsson M, Jensen U, Ringh M, et al. Coronary angiography in out-of-hospital cardiac arrest without ST elevation on ECG: Short- and long-term survival. $\mathrm{Am}$ Heart J 2018; 200: 90-95.

20. Staudacher II, den Uil C, Jewbali L, van Zandvoort L, Zijlstra F, Van Mieghem N, et al. Timing of coronary angiography in survivors of out-of-hospital cardiac arrest without obvious extracardiac causes. Resuscitation 2018; 123: 98-104.

21. Yamashina Y, Yagi T, Ishida A, Mibiki Y, Sato H, Nakagawa $\mathrm{T}$, et al. Differentiating between comatose patients resuscitated from acute coronary syndrome-associated and subarachnoid hemorrhage-associated out-of-hospital cardiac arrest. J Cardiol 2015; 65: 508-513.

22. Kothavale A, Banki NM, Kopelnik A, Yarlagadda S, Lawton MT, Ko N, et al. Predictors of left ventricular regional wall motion abnormalities after subarachnoid hemorrhage. Neurocrit Care 2006; 4: 199-205.

23. Kim YJ, Min SY, Lee DH, Lee BK, Jeung KW, Lee HJ, et al The role of post-resuscitation electrocardiogram in patients with ST-segment changes in the immediate post-cardiac arrest period. J Am Coll Cardiol 2017; 10: 451-459.

24. Henry TD, Granger CB. Out-of-hospital cardiac arrest: To CT or not to CT? JACC Cardiovasc Interv 2017; 10: 460-461.

25. Christ M, von Auenmueller KI, Noelke JP, Sasko B, Amirie S, Trappe HJ. Early computed tomography in victims of nontraumatic out-of-hospital cardiac arrest. Intern Emerg Med 2016; 11: $237-243$.

26. Prout R, Nolan J. Out-of-hospital cardiac arrest: An indication for immediate computed tomography brain imaging? Resuscitation 2009; 80: 969-970.

27. Mauriello A, Servadei F, Zoccai GB, Giacobbi E, Anemona L, Bonanno E, et al. Coronary calcification identifies the vulnerable patient rather than the vulnerable plaque. Atherosclerosis 2013; 229: $124-129$.

28. McCarthy JH, Palmer FJ. Incidence and significance of coronary artery calcification. Br Heart $J$ 1974; 36: 499-506.

29. Hecht HS. Coronary artery calcium scanning: Past, present, and future. JACC Cardiovasc imaging 2015; 8: 579-596.

30. Greenland P, Bonow RO, Brundage BH, Budoff MJ, Eisenberg MJ, Grundy SM, et al. ACCF/AHA 2007 clinical expert consensus document on coronary artery calcium scoring by computed tomography in global cardiovascular risk assessment and in evaluation of patients with chest pain: A report of the American College of Cardiology foundation clinical expert consensus task force (ACCF/AHA writing committee to update the 2000 expert consensus document on electron beam computed tomography) developed in collaboration with the Society of Atherosclerosis Imaging and Prevention and the Society of Cardiovascular Computed Tomography. J Am Coll Cardiol 2007; 49: 378-402.

31. Kim SM, Chung MJ, Lee KS, Choe YH, Yi CA, Choe BK Coronary calcium screening using low-dose lung cancer screening: Effectiveness of MDCT with retrospective reconstruction. AJR Am J Roentgenol 2008; 190: 917-922.

32. Arcadi T, Maffei E, Sverzellati N, Mantini C, Guaricci AI, Tedeschi C. Coronary artery calcium score on low-dose computed tomography for lung cancer screening. World J Radiol 2014; 6: $381-$ 387.

\section{Supplementary Files}

Please find supplementary file(s);

http://dx.doi.org/10.1253/circrep.CR-19-0055 